\title{
Enhancement of Photocatalytic Activity of ZnO Thin Films by Electrochemical Reduction
}

\author{
Koji Abe \\ Department of Electrical and Mechanical Engineering, Nagoya Institute of Technology, Gokiso, \\ Showa, Nagoya 466-8555, Japan \\ E-mail: abe@nitech.ac.jp
}

Received: 10 May 2021 / Accepted: 28 June 2021 / Published: 10 September 2021

\begin{abstract}
Photocatalytic activity of zinc oxide ( $\mathrm{ZnO})$ films under UV irradiation was enhanced by electrochemical reduction in an aqueous solution containing phosphoric acid and potassium chloride. The photocatalytic activity of the $\mathrm{ZnO}$ films depended on the electrochemical reduction time. The $\mathrm{ZnO}$ film with the electrochemical reduction for 20 min exhibited the highest photocatalytic activity for the decomposition of methylene blue (MB). The removal efficiency of MB in the solution was $96.5 \%$ after 180 min light irradiation. The photocatalytic activity of the $\mathrm{ZnO}$ film with the electrochemical reduction for $20 \mathrm{~min}$ was about five times higher than that of the $\mathrm{ZnO}$ film without the electrochemical reduction. The enhanced photocatalytic activity of the $\mathrm{ZnO}$ film was relatively stable throughout five consecutive cycle experiments. As the electrochemical reduction treatment is performed at room temperature, it is a very simple and effective way to improve the photocatalytic activity of $\mathrm{ZnO}$ films.
\end{abstract}

Keywords: zinc oxide, photocatalyst, electrochemical reduction, metal nanoparticle

\section{FULL TEXT}

(C) 2021 The Authors. Published by ESG (www.electrochemsci.org). This article is an open access article distributed under the terms and conditions of the Creative Commons Attribution license (http://creativecommons.org/licenses/by/4.0/). 